\title{
Hablando histéricamente: La ciencia de la locura en Feliz Nuevo Siglo Doktor Freud de Sabina Berman y Nadie me verá llorar de Cristina Rivera Garza
}

\author{
EMILY HiNd
}

Universidad de Wyoming

El reto de pensar más allá de uno de los estudios más influyentes sobre la literatura escrita por mujeres, La loca del desván o en su título original The Madwoman in the Attic de Sandra M. Gilbert y Susan Gubar, encuentra extenso apoyo en dos ejemplos recientes de literatura por autoras mexicanas. Como muchos saben bien, Gilbert y Gubar elaboran una teoría de la doble figura femenina, dividida entre ángel y monstruo, en obras literarias escritas en inglés por autoras que, en su mayoría, vivían durante el siglo XIX, cuando el uso de la pluma se juzgaba más apropiado para los hombres. Por la flexibilidad y coherencia de la teoría de la "loca del desván", la premisa de Gilbert y Gubar todavía podría servir como un método para entender a las protagonistas afligidas en la obra de teatro Feliz Nuevo Siglo Doktor Freud (2001) de Sabina Berman y la novela Nadie me verá llorar (1999) de Cristina Rivera Garza. Estas dos obras se inspiran en las narrativas históricas sobre "locas" y contemplan a éstas como potencialmente adelantadas a su tiempo, un nuevo tipo de mujer. Berman dramatiza el manuscrito de Freud acerca de su paciente "Dora", publicado en 1905 bajo el título poco poético Fragmento de un análisis de un caso de histeria. De manera parecida, en su tesis doctoral y en sus artículos eruditos, $\mathrm{Ri}$ vera Garza estudia el escenario histórico de su novela, el manicomio La Castañeda, que se construyó durante el porfiriato y ahora desaparecido.

El éxito considerable de la primera novela de Rivera Garza se refleja en las dos ediciones y los tres premios importantes con que se ha ga- 
lardonado a Nadie me verá llorar. ${ }^{1}$ La obra de teatro de Berman, Feliz Nuevo Siglo Doktor Freud, ha sido un éxito en taquilla y se celebró la representación número doscientos a finales de febrero de 2002.

En junio de ese año, la obra se trasladó del Teatro Orientación al Teatro Xola, una instalación de igual importancia. Relevante en estas recepciones entusiastas es el hecho de que el público original de la novela y de la obra de teatro contempla los temas fin de siècle durante el cambio de milenio. En ambas obras mexicanas, las protagonistas experimentan la adolescencia al final del siglo XIX y mueren a la mitad del siglo Xx. Más específicamente, la figura histórica de Ida Bauer, conocida como Dora en el manuscrito de Freud y en la obra de teatro de Berman, vivió de 1882 a 1945, mientras que el personaje de Matilda, basado en una paciente real, vive de 1885 a 1958.

Las transiciones análogas a cada nuevo siglo, que atestiguan el público y los personajes adolescentes, facilitan una meditación comparativa entre las normas sociales y científicas durante cada período. En un texto que fortuitamente respalda esta idea, Berman ha comentado que el libro de Freud sobre Dora originalmente le atrajo por el contexto del nuevo milenio. ${ }^{2}$ El juego de los siglos cambiantes aparece en el título de la obra, tomado de la felicitación de Dora en el diálogo. Cuando se repite en el título, "Feliz nuevo siglo, Doktor Freud" se transfor-

${ }^{1}$ Nadie me verá llorar ha recibido el Premio Nacional de Novela José Rubén Romero 1997, el Premio Nacional de Novela IMPAC-CONARTE-ITSEM 2000 y el Premio Sor Juana 2001.

${ }^{2}$ En una entrevista Berman recuerda:

fue hasta diciembre de 1999 que en una librería de viejo volví a ver el Caso Dora; me guiñó el ojo, lo compré y vi que estaba fechada precisamente en 1900, es decir, en el tránsito a otro siglo y como estaba preocupada, como todos, por el tránsito al nuevo siglo, lo leí (Del Río: 9).

Berman describe el volumen del caso Dora como relacionado con el año 1900, pero el año de publicación es 1905. Rivera Garza coquetea con errores igualmente pequeños. Aunque su personaje Eduardo contempla La interpretación de los sueños como publicado en 1900, en realidad el libro apareció en noviembre 1899 y sólo lleva el año 1900 (Decker: 235 nota 8). Así es cómo la Dora de Berman puede pedir a Freud que firme una copia del libro antes del año 1900, en el que ha empezado la obra de teatro. El análisis del error cronológico más importante en Feliz Nuevo Siglo aparece en el cuerpo del presente ensayo. 
ma para el público en una alusión ambigua a ambos "nuevos" siglos, el xx y el XxI. En cualquier caso, Freud parece incapaz de ver más allá de la opinión machista del siglo XIX respecto a las mujeres y no vislumbra lo que otro personaje, la contemporánea de Freud, Lou Andreas Salomé, se pregunta: “qué tal si Dora es una nueva mujer?” (25). Berman juega de manera más directa que Rivera Garza con la transición paralela de siglos, aunque la protagonista de Nadie me verá llorar también anticipa a la mujer "liberada".

Los textos mexicanos contemplan, pues, una locura ambigua, a diferencia de la "tradición” de la loca del desván, como la designan Gilbert y Gubar, la cual generalmente retrata a una loca con menos matices de cordura (464). Charlotte Brontë describe el personaje de Bertha, la orate original que literalmente vive atrapada en el desván en Jane Eyre (1847) de tal manera que los lectores comprenden inequívocamente la locura de Bertha. La exageración es tal que la escritora Jean Rhys halla razones para escribir una novela compasiva, Ancho mar de los sargazos o The Wide Sargasso Sea (1966), para explicar cómo viene a ser esa mujer monstruosa. Las autoras mexicanas, ambas lectoras y viajeras internacionales, heredan el trabajo de Brontë y de Rhys además de los efectos de la desconstrucción, el revisionismo histórico y la moda de "political correctness", junto a una elevada sensibilidad lingüística hacia los marginados. Quizás por estas influencias Rivera Garza y Berman se esmeran por cuidar que las etiquetas "loca" y "cuerda" no se entiendan como mutuamente exclusivas y por consiguiente las mujeres "locas" a veces parecen más cuerdas que sus médicos.

Los médicos en búsqueda de la fama en estos textos mexicanos adoptan ciencias, de la frenología al psicoanálisis, que no inspiran más confianza como narraciones veraces que las historias imaginativas de la nueva mujer que Rivera Garza y Berman cultivan.

El hecho de que la narración de Rivera Garza coloque la terminología científica sólo en las bocas de los tontos y los antagonistas, indica el rechazo de la historiadora hacia las pretensiones de una verdad científica. También en la obra de Berman la ciencia misoginista se enuncia exclusivamente a través del personaje del médico, Freud. La ambición y la mentira disfrazada de ciencia que los médicos evidencian, acompañan su intento de romper el espíritu independiente de las protagonistas. Las ganas de Freud por dominar a Dora operan en varias escenas, incluyendo la que muestra la despedida de Dora a Freud y el 
consecuente "furor interpretativo" del médico (36). De manera semejante, Rivera Garza crea el personaje del tío Marcos, un médico creyente en el darwinismo social que intenta someter a su sobrina, Matilda, a la higiene más estricta. Esta práctica basada en la ciencia del día va en contra de la lógica, y no se le ocurre a Marcos que él comparte los mismos genes inferiores que su sobrina. Tampoco comprende el médico que sus métodos están apagando la iniciativa e inteligencia de su sobrina. Como narra Rivera Garza:

Cuando el tío Marcos vio sus ojos [los de Matilda] una mañana del invierno de 1904 se sintió satisfecho de su obra. Las pupilas que alguna vez miraron con asombro y temor confundidos, caían ahora con precaución sobre todas las cosas. Entonces supo con certeza que la ciencia y la disciplina habían finalmente derrotado a los fantasmas etílicos que destrozaron las vidas de Santiago y Prudencia Burgos [los padres de Matilda] (113).

La curiosidad intelectual de Matilda parece haberse extinguido por su papel como sirvienta, pero dado un tiempo, Matilda se rebelará y se convertirá en obrera, prostituta y hasta artista. La revisión de las nociones populares de estas "locas" repite en cierto sentido el anacronismo de los siglos paralelos. No sólo se comparan los dos períodos, sino que también se confunden al trasladar al pasado la política de nuestra época para juzgar a los médicos y simpatizar con las perdedoras de entonces.

El rechazo de Freud y el cuestionamiento de la ciencia evidentes en los textos mexicanos proveen la excusa para disgregar el análisis de la estructura desarrollada en La loca del desván. Aunque sería posible adaptar la dicotomía ángel/monstruo de Gilbert y Gubar para catalogar a la nueva mujer y a la loca, el desafío mayor radica en el esfuerzo de estudiar la manera en que los textos mexicanos exceden los confines del análisis de La loca del desván. La desconfianza mexicana que revisa rigurosamente la ciencia contrasta con la técnica de Gilbert y Gubar que recluta ideas freudianas al servicio de fines feministas. Gilbert y Gubar reinterpretan el concepto misoginista y freudiano de la envidia fálica como una metáfora para la castración social de las mujeres y de este modo implican la legitimidad de la teoría freudiana (234, 272273). Queda como tema de discusión si la referencia freudiana es en 
realidad necesaria, es decir, si al reestructurar la obra freudiana como metáfora, Gilbert y Gubar retienen adecuadamente el sentido original de la teoría y así justifican la presencia de Freud en la crítica. Un segundo empleo de Freud por Gilbert y Gubar funciona como un atajo lingüístico para analizar imágenes. Al describir un mueble o una herida como simplemente "freudiano/a", las escritoras presuponen dos ideas: la familiaridad del lector con la teoría y la relevancia anacrónica de la teoría psicoanalítica aplicada a la escritura de mujeres del siglo XIX (330-344). Es precisamente esta pretensión a la validez universal implícita en tales aplicaciones del pensamiento freudiano lo que perturba a la historiadora feminista Joan W. Scott.

Scott repudia la manipulación anglo-americana y francesa de Freud en el campo de las investigaciones históricas porque la presencia de la teoría freudiana impide la introducción de una noción de "especificidad y variabilidad históricas” (1064). Se podría suponer que también los estudios literarios se beneficiarán de la misma atención a lo particular. Un repaso breve del trabajo de algunas intelectuales de diversos campos muestra que Scott cuenta con muchas críticas con las cuales debatir. En 1999, la influyente crítica feminista de arte, Griselda Pollock, publicó el análisis fuertemente freudiano, Differencing the $\mathrm{Ca}$ non: Feminist Desire and the Writing of Art's Histories. El uso de una teoría con raíces en el misoginismo - y que ahora ha sido descartada por los psicólogos y psiquiatras - para librar la historia del arte de su tradición machista parece contradictorio. Otro ejemplo es el ensayo sobre la Dora de Freud, en que la crítica feminista Toril Moi sugiere que tal como Edipo, Freud está atormentado por una "ansiedad terrible" que se llama "el miedo de la castración" (195). El aprovechamiento de Freud para analizar a Freud tal vez parezca un encierro demasiado estricto a los lectores dispuestos a pensar fuera de los paradigmas freudianos.

Para poner un ejemplo final, la biografía de Dora por Hannah S. Decker ofrece una de las investigaciones más lúcidas de la relación entre Freud y Dora, aun cuando Decker hace uso de conceptos freudianos para criticar la teoría freudiana. Resume el caso de Dora como "un ejemplo conmovedor de la influencia mutua de los sentimientos intensos, sumergidos de la paciente y del analista", o en el lenguaje psicoanalista, un ejemplo de la contratransferencia. Decker escribe que el descubrimiento y el amansamiento del fenómeno de la contra- 
transferencia representa uno de los mayores retos para los terapistas y para todos los médicos (193). La validez de la contratransferencia en la escritura de Decker queda sin cuestionar, a pesar de su larga exploración de las deficiencias de Freud en su tratamiento de Dora.

En contra de estas tendencias a favorecer la teoría de Freud, las escritoras mexicanas se rehusan a emplear lo freudiano como base teórica e intentan eludir la concomitante perspectiva homogénea y muchas veces masculinista. Rivera Garza y Berman investigan meticulosamente el contexto histórico de sus obras y así respetan la especificidad y variabilidad que Scott siente ausentes del análisis freudiano, aun cuando juzgan a los personajes según las simpatías de hoy. Las investigaciones históricas evidentes en los textos mexicanos merecen cuidadosa atención porque la discrepancia entre la historia y la narración de esa historia muestra la nueva postura de Rivera Garza y Berman respecto de las ideas circulantes en la época de Freud. Esta discrepancia también les podría distinguir de las críticas que emplean la teoría freudiana con intenciones feministas.

En un correo electrónico a la autora, Rivera Garza afirma la autenticidad de los pasajes en la novela impresos en letra distinta como citas de los documentos verdaderos anotados por y acerca de los pacientes de La Castañeda:

La información "básica" [...] está tomada literalmente de su expediente médico [de la paciente]: fecha y lugar de nacimiento, edad, profesión, descripción de síntomas — todo lo demás es ficción: lo que pasó en la fecha y lugar de nacimiento, profesión, relaciones, amores, desamores, viviendas, lugares, etc. Los textos en tipografía distinta [...] en el capítulo [tres] de "Todo es lenguaje" son copiados/transcritos directamente de expedientes médicos, así como lo es el último capítulo (de puño y letra de Matilda — pseudónimo—- por supuesto) del libro.

El doble papel de Rivera Garza como escritora de ficción e historiadora con un puesto académico en una universidad estadunidense le permite reaccionar con versatilidad a las críticas freudianamente feministas previamente citadas. Este papel doble justifica una lectura de Nadie me verá llorar que busca las huellas de una historiadora y una novelista para encontrar el momento en que las dos perspectivas difieren. Como narrativa de ficción, el punto de inicio de Nadie me verá 
llorar ocurre con las preguntas asentadas en las primeras páginas de la novela: “¿cómo se convierte uno en fotógrafo de locos?” y “¿cómo se convierte en una loca?”. Estas preguntas se suman con la de “¿cómo se convierte uno en fotógrafo de putas?” para propiciar las respuestas como la materia de la novela. Por otro lado, la semilla de la novela como obra histórica aparece mucho después, en la forma del expediente médico con el diagnóstico oficial para la protagonista (91-92). Este doble enfoque, tal vez explicable como contestación de una novelista a la inspiradora fuente histórica y como respuesta de una historiadora al estado incompleto y no confiable de esa misma información, extiende una extraña tensión narrativa al texto. El resultado final es la irracionalidad: la historiadora y la novelista respetan tramas en oposición.

Un estudio atento de Nadie me verá llorar demuestra una contradicción fundamental al relatar la naturaleza de los síntomas de la protagonista. La narración tampoco concuerda respecto a las indicaciones de salud o enfermedad que tales síntomas señalan. Mientras el documento de La Castañeda se queja de que la paciente en quien se basa Matilda "habla demasiado" y que sufre "logorrea", los discursos supuestamente "incoherentes e interminables" de Matilda mencionados en el expediente médico son comprensibles en la novela (92). De hecho, no es el expediente ni el médico Eduardo, sino el fotógrafo residente de La Castañeda, Joaquín, quien logra encontrar sentido en el pasado de Matilda. La adicción a la morfina de Joaquín y su preferencia por la compañía de las prostitutas y los internos del manicomio sobre su herencia, lo hace a la vez un investigador improbable y un candidato creíble para la interpretación de la narrativa de Matilda como una historia verdadera. La voz de Joaquín refleja en gran parte la voz de la novelista, con la excepción de las lecturas en la biblioteca que realiza Joaquín obedeciendo a la afición de la historiadora Rivera Garza. Así, Joaquín representa la confluencia de la doble perspectiva narrativa. Como prueba de la revisión de la historia dentro de la novela que en última instancia se torna irracional, Joaquín ofrece su pañuelo a la joven Matilda durante su primer viaje a la capital, antes de que Joaquín la conozca por primera vez cuando Matilda ya es prostituta. La presencia anacrónica de Joaquín aparece tres veces en la narración de esa escena e insiste en el artificio de la investigación histórica cuando pretende narrar fielmente un pasado ya irrecuperable. La primera aparición de Joaquín no llama la atención sobre la imposibilidad de su 
presencia; el pañuelo ofrecido en anonimato tiene sus iniciales J.B. (54). Con las dos referenciales adicionales, el anacronismo pierde sutileza y la narración histórica se presenta como digna de dudarse $(65,72)$.

Después de investigar, o medio inventar, la historia de Matilda, Joaquín la invita a salir de La Castañeda y ocupar la casa abandonada de la familia de Joaquín. Allí Matilda accede a su impulso de hablar incesantemente en una purificación mental que recuerda la cura desarrollada por el Doktor Freud de Berman, o sea, "the talking cure". Sin embargo, en lugar de recobrar su cordura después de tanto hablar, Matilda parece vaciarse. En esta condición achacosa, Matilda deja solo a Joaquín y regresa, al parecer permanentemente, a La Castañeda. Esta salida y regreso al manicomio plantea claramente la contradicción narrativa que se plantea con la aparición anacrónica de Joaquín examinada antes. Durante el proceso de enloquecimiento más allá de las paredes de La Castañeda cuando se queda con Joaquín, no sólo Matilda sino también el lenguaje se hace irrazonable. Los deseos de Matilda de hablar se debilitan a la vez que atenúan el significado y la consecuencia:

Cada vez hay menos cosas que decir. [...] Todo es insignificante. Los principios y los finales han quedado atrás. Nada tiene consecuencia. Un reloj de pulsera es un reloj de pulsera. Una túnica de seda es una túnica de seda. El desierto sólo es el desierto. La tautología es la reina de su corazón (198). ${ }^{3}$

La idea de que las palabras tienen un solo significado coincide con la propuesta de que las palabras no tienen ningún significado. Anteriormente, la documentación de la paciente a quien Matilda representa en la novela describe cómo ella usa términos rebuscados "a los cuales pretende dar otro significado" (92). Contra la evidencia recogida por la historiadora Rivera Garza —el expediente y las cartas irracionales de la paciente con que la novela concluye-, como novelista Rivera Garza propone que Matilda pierde su salud psicológica cuando ya no desea hablar ni torcer el lenguaje. Como señala la narración cerca del final de la novela, "el silencio es la burla perfecta de la razón” (206).

\footnotetext{
${ }^{3}$ De la misma manera que Matilda, el doctor Eduardo se distingue a solas de los pacientes de La Castañeda con su creencia en el significado unívoco lingüístico: "Una mano es una mano. Una jeringa es una jeringa. La tautología es la reina de su corazón, la única” (87).
} 
La contradicción en la novela entre la Matilda que está enferma por hablar demasiado y la Matilda que está enferma de silencio, imposibilita una diagnosis certera y frustra cualquier tentativa crítica de solucionar la novela; ninguna interpretación ni jerarquía de clasificación conquistará una obra anárquica. Ningún teórico encontrará la clave para Matilda porque es un enigma sin explicación. Quizá de esta forma Rivera Garza elude la trampa en que caen las críticas que adoptan la teoría freudiana y terminan dando la razón a la ciencia arraigada en el pensamiento machista del siglo XIX. Rivera Garza demuestra que otra burla perfecta de las que buscan la razón es la contradicción imposible de solucionar. El conflicto irracional entre la Matilda que cae en el silencio y regresa al manicomio y la Matilda que no puede detener el flujo de palabras hasta su muerte en la misma institución produce un aumento de sensibilidad y responsabilidad por parte de las reacciones críticas a Nadie me verá llorar, la cual desde el título sostiene la dignidad de la paciente. En esta novela, ni lector ni paciente tienen la razón.

Al entrar el siglo XXI, Rivera Garza ejemplifica el caso de una historiadora y novelista que genera un texto enlazado con numerosas citas de otras fuentes en el estilo documentado y lógico de una investigadora y, no obstante, mina la confianza que es típico otorgar a un texto documentado al sembrar la contradicción interna. Mientras Rivera Garza despliega una irracionalidad invencible, Berman basa su obra en el optimismo frente a la seducción de lo racional que muestran las críticas que aplican el pensamiento freudiano a los argumentos feministas. Este optimismo se sostiene en el rechazo de la sofisticación lógica que pretenden las críticas. El optimismo de Berman se encarna en la figura de Lou Andreas Salomé, quien pronuncia la metáfora con que se puede entender Feliz Nuevo Siglo. Salomé propone que en "la casa de cultura", Freud, el pensador de inmensa creatividad, cava un sótano con su teoría de lo inconsciente:

[L]a cultura es una casa hecha de ideas y no podemos pensar nada fuera de esa casa. Un genio sin embargo piensa nuevas cosas: agrega una habitación o dos a la casa. Freud agregó todo un sótano: nos descubrió el sótano de nuestra conciencia: el inconsciente (26).

A primera vista, la imagen de "la loca del sótano" se distancia poco de la teoría de Gilbert y Gubar. Posiblemente, La Castañeda de Rivera 
Garza representa otro sótano parecido, éste lleno de las vergüenzas de la ciudad de México. Una salida de semejante corto-circuito crítico estriba en una mayor contemplación de la portavoz de este elogio de Freud como el arquitecto sotánico.

Salomé representa un feminismo pseudo-invisible en la obra de Berman porque difiere de la opinión de Freud a través de apartes pronunciados desde una posición marginada del escenario. Como observa Jacqueline Bixler, "como mujer, y peor aun, como mujer de ciencia a fines del siglo XIX, Lou no puede ocupar el centro del escenario, así que hace sus comentarios desde el margen y a veces sólo al público" (4). Por otro lado, en el récord histórico tal como lo interpreta la biógrafa Biddy Martin, Salomé es una intelectual prolífica y versátil que no apoya la visión freudiana de la mujer. Salomé publicó quince novelas y colecciones de prosa breve, estudios extensos, y más de cien ensayos y reseñas sobre temas diversos, incluyendo el feminismo y el psicoanálisis. En contraste con Freud, Salomé sostiene que las calidades masculinas y femeninas coexisten en las mujeres, haciéndolas completas y auto-suficientes aun sin compañero. Martin subraya la ambivalencia del análisis feminista de Salomé porque nunca reta directamente las presunciones sociales, como la de la heterosexualidad (5). No obstante, Salomé acepta el lesbianismo. Salomé parece una filósofa cautelosa que, a pesar de esa cautela, logra desmentir el pensamiento freudiano; ella se niega a considerar el psicoanálisis como una ciencia natural y resiste el lenguaje técnico y científico tan querido por Freud y sus seguidores (195).

El reconocimiento del papel histórico de Salomé complementa el respeto que el público aprende a sentir por ella después de verla responder ingeniosamente al machismo de Freud. Por ejemplo, mientras Freud conversa con ella, Salomé cavila sobre la sinceridad de la creencia freudiana de que las mujeres son inferiores: "Sólo me pregunto [...] por qué un genio discute ideas con un castrato" (26). En la obra de Berman, Salomé se comunica de manera anacrónica con Gloria Steinem, y así también se diferencia de Freud: Salomé ve más allá del siglo que limita al médico. Para sondear más la importancia de Salomé en Feliz Nuevo Siglo, la metáfora de la "casa de cultura" y el sótano de Freud es clave.

La metáfora de Salomé, aunque pronunciada en el contexto de una Casa Europea de Cultura, puede contener a todas las sociedades que 
han sido influidas por la teoría de Freud y, como resultado, la metáfora connota una domesticidad o una familia casi global. Aunque el poder masculino controla la Casa durante la vida de Salomé como su cauto feminismo implica, la Casa de Cultura coloca a Freud en un dominio asociado con las mujeres. Además del inconsciente, cuya existencia es asunto de debate, el sótano de Freud tal vez se añade para controlar a la mujer en esta Casa compartida en que podría llegar a adquirir autoridad parecida a la de los hombres. Es cierto que, a principios del nuevo siglo, "la loca del desván" amenazaba con extender su presencia incómoda a otro espacio más imperioso, digamos, un cuarto propio.

En relación con el sótano de Freud, parece importante indicar que la fama de Salomé sigue siendo exigua. Como nota Martin, el renombre de Salomé como novelista y ensayista, se había desvanecido a la hora de su muerte y desde entonces poco de su trabajo ha sido reimpreso (19). En cierta forma, Berman ha sacado a Salomé del sótano construido por la teoría misoginista de Freud y sus seguidores. A pesar de la desaparición de Salomé del ámbito popular, la obra de Berman no provee mucha información acerca de las actividades profesionales de Salomé. Es más, durante mucho de su tiempo en el escenario, se encuentra tejiendo y nunca escribe ni menciona sus obras. Esta carencia de atención a la presentación formal de Salomé ante un público que probablemente la desconoce pide todavía otro análisis respecto a la identidad de los que habitan el sótano.

Aunque la interpretación del sótano como residencia de Salomé es posible, también es cierto que Salomé está en el escenario y cuerda, mientras el público se sienta en una posición más baja y en la oscuridad: una referencia al sótano mismo. Se supone que un público activo descifrará la metáfora que Berman ofrece y, al hacer más investigaciones sobre el papel de Salomé, se trasladará a un lugar más saludable. Para aclarar la relación histórica entre Salomé y el optimismo, viene al caso repasar la reacción de Freud hacia ella. En la biografía, Martin detalla la mistificación de Freud respecto a las ideas de su antigua discípula:

Freud comentó muchas veces de su propia inhabilidad de seguir aspectos de la obra de Salomé, específicamente lo que vio como las transformaciones y elaboraciones poéticas, filosóficas y sintéticas de los conceptos psicoanalíticos y, sobre todo, su optimismo indomable (195). 
El "optimismo indomable" de Salomé, por mucho que esté enterrado en el pasado histórico, señala un aspecto estratégico de importancia en la obra de Berman. Una actitud optimista cohesiva precisa de cierta superficialidad para fusionar la propaganda feminista con el análisis histórico. Ello es particularmente cierto en el análisis de la vida de Dora, una existencia más adecuada para reforzar una postura pesimista a causa del papel social sofocante y, según las investigaciones de Decker, de unos tratamientos médicos incompetentes que incluían sesiones extensas de electroterapia e hidroterapia (102). El optimismo de Berman, articulado con confianza al comienzo de la obra por la proclamación de un "nuevo" siglo, se apoya sobre la técnica del anacronismo y sobre lo que se podría describir como un método de observación adolescente.

El anacronismo de Berman también se encuentra en la novela de Rivera Garza con su representación del tiempo ahistórico. Las autoras incorporan ese anacronismo porque les permite imaginar una nueva mujer dentro del esquema histórico que controla el desenlace de la trama, además de desafiar la pátina de racionalidad con que se cubre la ciencia misoginista. Valerse del anacronismo no resulta una técnica sutil en ninguna de las dos obras. ${ }^{4}$ Feliz Nuevo Siglo otorga a la actriz

\footnotetext{
${ }^{4}$ En Nadie me verá llorar, el anacronismo caracteriza a Matilda y a su amigo, Joaquín. Matilda y Joaquín operan fuera del tiempo histórico. Rivera Garza marca el abismo que separa a Matilda y Joaquín de la historia con pasajes didácticos. Con disculpas a la profesora Rivera Garza, la siguiente cita salta la lección de historia con el propósito de repetir sólo la a-historicidad que afecta a los personajes:
}

Matilda Burgos y Joaquín Buitrago se han perdido todas las grandes ocasiones históricas. Cuando la revolución estalló, ella estaba dentro de un amor hecho de biznagas y aire azul, y él en la duermevela desigual de la morfina (175).

Rivera Garza continúa con una enumeración de los sucesos históricos que los personajes se pierden, pero que los lectores deben tener en cuenta. El pasaje concluye: "Los dos anduvieron siempre en las orillas de la historia, siempre a punto de resbalar y caer fuera de su embrujo y siempre, sin embargo, dentro. Muy dentro" (176). Otros ejemplos de esta a-historicidad incluyen el pasaje en que Rivera Garza retrata el momento quizá preciso de la salida de la historia que efectúa Joaquín:

Como si él no fuera en realidad el único fotógrafo de su generación que hubiera tomado placas de generales, adelitas, presidentes o masacres. Como si aquella no- 
con el papel de Dora una función triple porque también toma los papeles de Ana Freud, la hija del Doktor y la futura psicoanalista, y Gloria Steinem, quien platica brevemente con Salomé. Con un anacronismo menos fuerte que el de Steinem, durante su despedida Dora informa a Freud que está vestida como George Sand (36). A su vez, la actriz que interpreta a Salomé duplica papeles al convertirse en la madre neurótica de Dora. De este modo, Berman incita al espectador a que imagine otro destino para Dora y su madre como mujeres competentes y profesionales, dados su papel y su siglo alternativo. El anacronismo surge de manera didáctica cuando Salomé dice a Steinem:

Esto lo estamos hablando en otro tiempo; cuando sucede esta conversación entre usted —una feminista de los años sesentas- y yo, Dora ya es un caso clínico célebre y yo llevo cuarenta años muerta (26).

Al no poder Freud ver más allá de su siglo, el artificio del anacronismo facilita una perspectiva alternativa esencial para la obra. Este anacronismo abraza lo irracional sin distorsionar el entorno histórico. Así, Berman se salva del problema de mucha crítica freudiana al respetar el contexto histórico específico sin pretender elaborar otra ciencia o teoría racional con que remplazar el sistema de Freud; la dramaturga crea una propaganda feminista que advierte sus propias imposibilidades.

Además del anacronismo, otra técnica necesaria para lograr el optimismo en Feliz Nuevo Siglo es un acercamiento simplificado a la situación histórica. Rivera Garza combate asimismo la tentación de reducir la complejidad histórica; esa tentación aparece en la aspiración de varios personajes a una relación matemática entre el significado y el significante. Matilda, y aun su médico Eduardo, se aferran a la deleitable estabilidad resultante de la idea de que "una mano es una mano". Los lectores se deben preguntar si consentir que la tautología gobierne el corazón, un gesto que ensayan ambos, la paciente y el médico, nos

che de 1908 al salir de El Templo del Amor no hubiera abandonado para siempre la historia (26).

Eduardo también sugiere que La Castañeda, o más bien sus habitantes, existen fuera de la historia (33). El anacronismo sirve a Rivera Garza igual que a Berman, porque con frecuencia la novela requiere las experiencias de Matilda fuera del tiempo para presentarla como independiente e imaginativa, pero no demente. 
acerca o nos aleja de la salud psicológica. En última instancia, las contradicciones de Nadie me verá llorar sugieren que tales simplificaciones quedan fuera de las posibilidades de una imagen fiel a la naturaleza del lenguaje. Las distintas necesidades temáticas de Berman, sin embargo, requieren la simplificación. El lenguaje que se evidencia abierto a una manipulación artera en ambas obras sirve en Feliz Nuevo Siglo para apoyar la idea de la verdad confiable. Si bien a Berman no le da miedo admitir una disminución de ambigüedades, tampoco teme burlarse del representante pretencioso del intelectual, Freud.

El Freud de Berman descarta la idea de que las palabras sólo tienen un significado. Este reconocimiento de la complejidad del lenguaje no incluye una admisión de la poca seguridad que suministran las palabras y así se reduce la complejidad de la presentación del lenguaje. Freud se aprovecha del carácter irresoluto del lenguaje para proclamarse intérprete maestro, el que sujeta los hilos que conectan el significado engañoso con el verdadero significante. Durante una conversación clave, Dora contesta que no, no ama a Herr K., el hombre que ha intentado agredirla sexualmente, y el Freud de Berman replica: "Pero Dora, en este caso, un No es un Sí”. Una Dora colérica responde, “¿¿En qué planeta un No es un Sí??? Luego, cuando Dora pregunta por el significado de "Sî”, Freud contesta: "Un Sí es un Sî”. Dora se da cuenta de que diga lo que diga, gana Freud (33). El humor de Berman lleva la escena a su clímax cuando Freud realiza una cirugía psicoanalítica al amputar el falo imaginario de Dora. En otras palabras, Freud "cura" a Dora al insistir en que considere la posibilidad de casarse con Herr K., su molestador y el hombre que más tarde arruina el escape de Dora a la universidad. La amputación también insinúa que Dora pierde "la pluma" con la cual uno tiene el derecho de manipular y simplificar el lenguaje a su beneficio. Históricamente, Freud nunca aceptó a Dora como paciente después de que ella terminó el tratamiento en la víspera del Año Nuevo.

Berman da fin a la obra con una suerte de epílogo en el que Dora, ya madura y psicológicamente débil, recibe el perdón de Freud por no haber permitido curarla junto con una negación de ella al pedido de reintegrarse como paciente (42). Para rescatar el optimismo encarnado por Salomé y Stienem, Berman cierra la obra con este comentario de Freud: "Una infelicidad [...] general y difusa [...] es el signo [...] de la buena adaptación" (43). En este sentido, la "cura" efectuada por 
Freud es exitosa, ya que Dora se convierte en un ama de casa infeliz. Sin embargo, este "final feliz" puede parecer un poco forzado. Si bien Freud no sostiene el optimismo, por lo menos su triunfo sobre la humillada Dora, deja implícita, no obstante, la importancia de la explotación freudiana del lenguaje. Esta manipulación lingüística reduce la ambigüedad y favorece la intención optimista de Berman haciendo posible la presentación de una verdad máxima y confiable.

A pesar de su preferencia compartida por las categorías inestables de la salud mental, Berman y Rivera Garza divergen respecto de la existencia de la verdad, tal como divergen también en cuanto al asunto del lenguaje. En Feliz Nuevo Siglo, Salomé y Freud concuerdan en que Dora, en virtud de su edad joven, está en contacto directo con la verdad (23). En la novela de Rivera Garza, la verdad es más difícil de definir, aunque el narrador mantiene la idea en el pensamiento: "Tal vez Matilda está en otro lado de la verdad” (24). Precisamente en qué consiste esta "verdad" y lo que contiene su "otro lado" es ambiguo..$^{5}$ Abogar por la verdad unívoca al final del siglo XX y principios del siglo XXI parece ingenuo, y la obra de teatro de Berman emplea tal pensamiento con la justificación de la presencia de una adolescente en el elenco, Dora. El público se encuentra libre para matizar el diálogo de Berman y se puede pensar que Dora está en contacto directo con la verdad porque sólo los jóvenes se atreven a creer en una verdad absoluta.

La postura simplificada de Dora, aunque no desprovista de confusión ni de infelicidad, refleja una energía y un optimismo no característicos de los adultos que se mueven en la esfera de influencia de Dora. Típica de una perspectiva adolescente, Dora a veces parece incapaz de distinguir personalidades individuales entre los adultos y los amontona en una sola categoría adversativa. La puesta en escena de la obra secunda este entendimiento superficial de otros al vestir a los personajes masculinos de la misma forma y al dividir a Freud en tres papeles que aparecen simultáneamente, como los demás actores, vestidos igual. ${ }^{6}$ El Freud histórico sentía presión por forzar la adaptación de

\footnotetext{
${ }^{5}$ El apoyo por el lenguaje estable en la novela no connota la veracidad. Eduardo miente cuando firma un documento afirmando la ausencia de morfina en el cuerpo de Joaquín a cambio de un soborno.

${ }^{6}$ No se debe pensar que Freud 1 y 2 representan el ello (id) y el superyó (superego) o algún recurso parecido porque Freud 1 y 2 no alcanzan la complejidad necesaria.
} 
Dora a los deseos de su padre, debido a que Herr F. pagaba los honorarios del médico. El hecho de que el actor que interpreta el papel de Herr F. también actúa como el doble de Freud revela la alianza de sus perspectivas. Hasta el perseguidor sexual de Dora, Herr K., se viste igual a los otros dos y tiene el papel de otro Freud y, en consecuencia, la similitud puede parecer exagerada, como el producto de una visión novata del mundo. Bixler reconoce esta similitud y se atreve a seguirla hasta sus últimas implicaciones: "El hecho de que los tres Freuds y los dos herrs se vean casi idénticos sugiere que todos los hombres son iguales; se ven iguales, y por ende, piensan igual" (4). En resumen, Berman tiende a restringir las áreas propensas al conflicto y a la complejidad para fortalecer el optimismo didáctico de su obra sin reducirse al argumento racional y sin pretensión de hacer otra ciencia.

Un comentario final sobre la exuberancia intencionalmente adolescente de Feliz Nuevo Siglo se relaciona con el uso constante de las comillas gesticuladas por parte de Dora, un gesto pueril que indica el reconocimiento orgulloso de la hipocresía en el mundo adulto. Otro motivo más sofisticado por el uso exagerado del gesto es el de atraer la atención sobre el carácter citado de la obra misma. Feliz Nuevo Siglo comienza con un epígrafe tomado de las obras de Freud y reproducido en el programa. También, cuando Freud aparece en triplicado, las afirmaciones lanzadas por Freud 1 y 2, por ejemplo "Freud dixit," evidencian este carácter de citas que tiene el texto de Berman (34). Como uno esperaría, Rivera Garza encuentra menos extenuante señalar el aporte textual gracias al género narrativo de la obra. Los epígrafes que sirven como introducción a cada capítulo y las citas dentro de los capítulos dan testimonio del catálogo previo de los textos elegidos. El texto de más relevancia citado en Nadie me verá llorar es la novela de Federico Gamboa, Santa, publicada en 1903. La concordancia y la discrepancia entre obra nueva y obra vieja indican la limitada innovación de las autoras mexicanas que sin embargo representa un paso más allá de algunas otras obras críticas.

En Nadie me verá llorar, la novela de Gamboa surte un axioma para la trama, ya que Matilda y su pareja mujer terminan asumiendo relaciones heterosexuales que recuerdan el rescate pasajero de Santa por parte del torero El Jarameño. Junto a este uso respetuoso del texto, los personajes de Rivera Garza se burlan de la historia de Gamboa. Matilda se rebela contra las leyes que regulan la prostitución y que Santa si- 
gue, y Matilda disfruta de la experiencia lesbiana que Santa teme. También Matilda y su compañera parodian de Santa un baile popular que la pareja llega a representar en un burdel de primera clase llamado "La Modernidad". El análisis de Santa y el de Fragmento de un análisis manifiestan que la Matilda de Rivera Garza y la Dora de Berman se convierten en ejemplos transitorios de la nueva mujer en el momento en que logran escapar de los anteriores lindes textuales. Este escape también sugiere la superación de las obras críticas de arte, de historia o de literatura que tienden a usar los viejos textos de perspectivas masculinistas como axioma, ya para comprobar la naturaleza del ser humano o para explicar una imagen, sin escapar muchas veces satisfactoriamente a un nuevo terreno textual. La libertad de Rivera Garza y de Berman de plasmar este escape tal vez se debe a los géneros imaginativos y por ende flexibles que emplean. La nueva mujer de las versiones mexicanas, sin embargo, no perdura en ambos textos. Matilda y Dora parecen haber renunciado a los posibles logros profesionales al final de sus historias, no por moralidad laxa ni por inteligencias débiles, sino como resultado de una recaída desventurada en los textos de hombres. ${ }^{7}$ El récord histórico, los arquetipos de ficción, y aun los diagnósticos escritos por los médicos cercenan la exploración exultante y más sostenida del papel de la nueva mujer.

Ya que se han comparado las maneras con que Rivera Garza y Berman intentan superar la visión tradicional de la "loca", se vuelve necesario considerar el grado de progreso que cada autora calcula de un siglo a otro. El entorno que estimula la crítica freudiana contemporánea y a las autoras mexicanas ¿marca una época realmente avanzada? La novela de Rivera Garza favorece el ahistoricismo en lugar del anacronismo extravagante que prefiere Berman y, como resultado, Nadie me verá llorar combina la comparación implícita entre siglos con lo irracional, para prevenir las conclusiones sobre las posibilidades del progreso. Frente a los que buscarían el avance de nuestros tiempos, Rivera Garza destaca lo absurdo de los personajes que creen en el progreso

\footnotetext{
7 Otra técnica importante en ambos textos es la coincidencia. El uso marcado de coincidencia tal vez sugiere que la discriminación contra las mujeres es tan gratuita que representa una postura narrativa casi increíble o inexperta. La coincidencia implica que el azar y no la razón determina el destino de Dora y de Matilda como "locas" infelices.
} 
social. ${ }^{8}$ Nadie me verá llorar resiste el feminismo más propagandístico de Berman y parece menos segura de que un "nuevo siglo" haya ocurrido.

La noción de progreso social en la obra optimista de Berman recibe un sustento fuerte. Las referencias a Gloria Steinem, George Sand, Lou Andreas Salomé y Ana Freud ponen al alcance del lector modelos relativamente positivos. Steinem en particular marca la transición histórica en favor de los derechos de la mujer. Por otra parte, a pesar del anacronismo, Feliz Nuevo Siglo es en último análisis una obra histórica, y el destino de Dora representa una vida estancada. El optimismo y la insistencia en la idea de progreso conduce a veces a Berman al error que Rivera Garza elude. Mientras que Nadie me verá llorar emplea la contradicción para evitar el estar al lado del diagnóstico oficial de Matilda, la crítica de Freud elaborada por Berman, que se completa con la glosa irreverente de la teoría freudiana respecto de las mujeres, no logra liberarse completamente de cierta simpatía hacia el médico. Según el caso, tal simpatía podría indicar un punto de vista maduro, o sea, el opuesto a la perspectiva adolescente sin matiz ya detallada. Por otro lado, los paralelos entre la obra de Berman y la de Freud incluyen la explotación de Dora. Freud utiliza a Dora para comprobar la validez de sus teorías. Además, al principio de la obra de Berman, Freud se queja de que la "morbosa Viena" lea su obra como un roman à clef (6). Berman se aprovecha también de la historia de Dora con cierta morbosidad cuando Dora se acurruca desnuda en la mesa de cirugía. Fotos de esta escena sirven para la publicidad y hasta se reproduce la imagen en un artículo en Tramoya (2001: 5-43). Dora aparece también, por primera vez en el escenario vestida con una falda pero, de la cintura para arriba, con un pequeño brassiere.

El marco cronológico de Berman acepta y corrige el texto de Freud en el mismo estilo que acepta y condena la explotación de Dora por el médico. En su análisis original, Freud añade erróneamente un año a la edad de Dora y se refiere a ella como de 19 años (Decker: 119). En la versión de Berman, Salomé dice que la edad de Dora es 17 años. En rea-

\footnotetext{
${ }^{8}$ En Nadie me verá llorar, los hombres, con la excepción de Joaquín, creen en el progreso. Son Cástulo, el combatiente revolucionario, Marcos, el médico positivista, Paul, el ingeniero, y Eduardo, el psiquiatra arribista. Sólo Paul llega a dudar del progreso, como se comprueba con su suicidio.
} 
lidad, cuando tenía 17 años, Dora comenzó el tratamiento con Freud y terminó la terapia menos de dos meses antes de cumplir los 18. Berman no corrige una segunda falla cronológica en el texto de Freud; él retrasa la acción un año. Berman repite la confusión cronológica de Freud y sitúa la despedida entre Freud y Dora el 31 de diciembre del año 1899 en lugar de 1900. Sin duda, Berman valora el impacto dramático sobre la exactitud histórica y algunas veces reproduce de modo incómodamente fiel los errores de Freud.

Para concluir, parece una resistencia a la crítica freudiana/feminista el rechazo por Rivera Garza y Berman del concepto de la infalibilidad científica y su negación a basar la psicología o las imágenes de sus obras en las teorías freudianas. La simpatía ocasional de Berman por el Doktor y la negativa de Rivera Garza por aventurar alguna opinión sobre el posible progreso social dificulta la declaración de que un siglo realmente nuevo ha comenzado a partir de los textos de Gilbert y Gubar. Se debe repetir lo inquietante que resulta la comodidad con que el doble que proponen Gilbert y Gubar pueda describir una distinción en los textos mexicanos entre la nueva mujer y la loca; por lo menos la división entre ángel y monstruo se ha vuelto más borrosa. Los extremos de personajes parecen haberse suavizado con el desvanecimiento de la popularidad de las oposiciones binarias.

Como último intento de trabajar más allá de la crítica de Gilbert y Gubar, se puede señalar que una respuesta a la cuestión del progreso se relaciona con los temas lésbicos. La novela de Rivera Garza y la obra de teatro de Berman insisten en el encanto de mujeres en personajes secundarios, a pesar del hecho de que las mujeres también se reprimen mutuamente. La aventura lesbiana de Matilda y la atracción sexual de Dora hacia Frau K. podrían ofrecer una medida para calcular el progreso feminista en nuestros tiempos. En Nadie me verá llorar y en Feliz Nuevo Siglo, Doktor Freud, la carencia de progreso ciertamente se presenta cuando las mujeres se oprimen mutuamente. Matilda nunca desarrolla su inclinación hacia una carrera en medicina no sólo por el machismo del tío Marcos, sino también por el de la doctora para quien trabaja Matilda como ama de llaves; esta doctora no procura la educación formal de Matilda. Asimismo, Frau K. no respalda la queja de Dora en el sentido de que Herr K. le ha besado y manoseado, cuando el padre de Dora, también amante de Frau K., se enfrenta con Herr K. Estas opresiones entre mujeres sugieren un anti-feminismo. 
Fuera de las relaciones amorosas entre mujeres, otra posible señal de progreso sería la función de la mujer como médico. Parece una coincidencia importante que ambas protagonistas expresen interés en la medicina. Dora pregunta acerca de la posibilidad de estudiar psicoanálisis y Matilda extrae una bala de un combatiente revolucionario que entra subrepticiamente en la recámara de la joven. Mientras las protagonistas logran a medias una relación feliz con otra mujer, no logran obtener una enseñanza formal como médicos. Si bien "la loca” viajó del desván al sótano en el presente trabajo, todavía se espera el viaje al otro lado del escritorio del médico para empezar un nuevo tomo en las tradiciones literarias de "la loca" y la crítica. Las obras mexicanas analizadas aquí anticipan ese paso, pero prefieren cuestionar la división absoluta entre locura y cordura en lugar de convertir "la loca" en doctora. Un cambio verdadero de siglos requiere el análisis de teorías más propicias para el feminismo. Al transgredir los actuales linderos textuales no se brinda meramente por un cambio de milenio sino por el intento de ver más allá de nuestros tiempos, como instruye Berman.

\section{BiBLIOGRAFÍA}

Berman, Sabina. "Feliz Nuevo Siglo Doktor Freud", en Tramoya: Cuaderno de teatro. México: Universidad Veracruzana. 58 (2001).

Bixler, JACQUeline. "La política del sexo o el sexo de la política en dos obras 'freudianas' de Sabina Berman y Jesusa Rodríguez”, en Teatro XXI. Argentina: Buenos Aires. 8.14 (2002).

Decker, Hannah S. Freud, Dora, and Viena 1900. Nueva York: The Free Press, 1991.

Del Río, Tayde. "El error de 'her Doctor', en $M$ en Reforma. (8 de julio de 2001)

Gilbert, Sandra M. y Susan Gubar. The Madwoman in the Attic: The Nineteenth Century Literary Imagination. New Haven: Yale University Press, 1984.

Martin, Biddy. Woman and Modernity: The (Life) Styles of Lou AndreasSalomé. Ithaca / Londres: Cornell University Press, 1991.

MoI, TORIL. "Representation of Patriarchy: Sexuality and Epistemology in Freud's Dora”, en Charles Bernheimer y Claire Kahane (eds.). In Dora's Case: Freud Hysteria-feminism. Nueva York: Columbia University Press, 1985. 
Pollock, Griselda. Differencing the Canon: feminist Desire and the Writing of Art's Histories. Nueva York / Londres: Routledge, 1999.

Rivera Garza, Cristina. Nadie me verá llorar. México: Tusquets, 1999.

SCOUT, JOAN W. "Gender: A Useful Category of Historical Analisis", en The American Historical Review. 91.5 (1986). 
